\title{
Assessment of Cytotoxicity, Anti-Inflammatory and Antioxidant Activity of Zinc Oxide Nanoparticles Synthesized Using Clove and Cinnamon Formulation - An In-Vitro Study
}

\author{
Subhashree Mohapatra ${ }^{1}$, Leelavathi L ${ }^{2}$, Rajeshkumar S. ${ }^{3}$, Sri Sakthi D. ${ }^{4}$, Jayashri P. ${ }^{5}$
}

\begin{abstract}
${ }^{1}$ Department of Public Health Dentistry, Saveetha Dental College, Saveetha Institute of Medical and Technical Sciences, Chennai, Tamilnadu, India. ${ }^{2}$ Department of Public Health Dentistry, Saveetha Dental College, Saveetha Institute of Medical and Technical Sciences, Chennai, Tamilnadu, India. ${ }^{3}$ Department of Pharmacology, Saveetha Dental College, Saveetha Institute of Medical and Technical Sciences, Chennai, Tamilnadu, India. ${ }^{4}$ Department of Public Health Dentistry, Saveetha Dental College, Saveetha Institute of Medical and Technical Sciences, Chennai,

Tamilnadu, India. ${ }^{5}$ Department of Public Health Dentistry, Saveetha Dental College, Saveetha Institute of Medical and Technical Sciences, Chennai, Tamilnadu, India.
\end{abstract}

\section{ABSTRACT}

\section{BACKGROUND}

Zinc oxide nanoparticles play a vital role in diagnostics, biomolecular detection, and microelectronics. Several conventional methods are used for synthesis of zinc oxide nanoparticles. But, toxic chemicals are required as capping agents to maintain stability, thus leading to toxicity in the environment. Thus, we need to shift to "green synthesis". Hence, this study was conducted to assess the cytotoxicity, antiinflammatory, and antioxidant activity of zinc oxide nanoparticles reinforced with clove and cinnamon.

\section{METHODS}

Cytotoxic effect, anti-inflammatory activity, antioxidant activity of zinc oxide nanoparticles reinforced with clove and cinnamon extract were assessed using Brine Shrimp Assay, Bovine Serum Albumin (BSA) and DPPH Assay respectively at $5 \mu \mathrm{L}, 10$ $\mu \mathrm{L}, 20 \mu \mathrm{L}, 30 \mu \mathrm{L}, 50 \mu \mathrm{L}$.

\section{RESULTS}

As the concentration increased, the cytotoxicity of the nanoparticles increased. Values for anti-inflammatory property of nanoparticles was higher than the standard values at all concentrations. Percentage of inhibition was highest at $40 \mu \mathrm{L}(91.1 \%)$ and $50 \mu \mathrm{L}(90.5 \%)$. The values for antioxidant property of nanoparticles was found to be higher than the standard values at all concentrations except at $50 \mu \mathrm{L}$. Percentage of inhibition was highest at $20 \mu \mathrm{L}(86.2 \%)$.

\section{CONCLUSIONS}

Zinc oxide nanoparticles reinforced with clove and cinnamon extract have a potential as an anti-cancer, anti-inflammatory and antioxidant agent and can be used as an alternative to commercially available products.

\section{KEY WORDS}

Zinc Oxide Nanoparticles, Clove, Cinnamon, Antioxidant, Anti-Inflammatory, Cytotoxicity
Corresponding Author:

Leelavathi L.,

Department of Public Health Dentistry, Saveetha Dental College, Saveetha Institute of Medical Technical Sciences, Chennai, Tamilnadu, India. E-mail: karleela81@gmail.com

\section{DOI: $10.14260 /$ jemds/2020/405}

Financial or Other Competing Interests: None.

How to Cite This Article:

Mohapatra S, Rajeshkumar S, Leelavathi L, et al. Assessment of cytotoxicity, antiinflammatory and antioxidant activity of zinc oxide nanoparticles synthesized using clove and cinnamon formulation-an invitro study. J. Evolution Med. Dent. Sci. 2020;9(25):1859-1864, 10.14260/jemds/2020/405 DOI:

Submission 25-02-2020,

Peer Review 23-04-2020,

Acceptance 30-04-2020,

Published 22-06-2020.

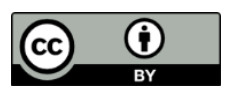




\section{BACKGROUND}

Nanotechnology is an emerging technology and has led to a new revolution in every field of science. ${ }^{[1]}$ This technology has been used in the fields of optics, electronics, and biomedical and materials sciences. Nanotechnology deals with nanoparticles that are atomic or molecular aggregates characterized by size less than $100 \mathrm{~nm}$. These are actually modified form of basic elements derived by altering their atomic as well as molecular properties of elements.[2]

Among the various inorganic nanoparticles available, Zinc Oxide ( $\mathrm{ZnO}$ ) has easy processing methods, is inexpensive, has wide range of applications and is a safe material. Due to these properties, Zn 0 pulls a particular interest among researchers.

Zinc Oxide nanoparticles play a vital role in diagnostics, biomolecular detection, microelectronics.[3] Several conventional methods are used for synthesis of zinc oxide nanoparticles like chemical reduction, ${ }^{44]}$ laser ablation,,5] solvothermal,[6] inert gas condensation,[7] sol-gel method.[8] Even though less time is utilized for synthesizing large quantities of nanoparticles using conventional physical and chemical methods, toxic chemicals are required as capping agents to maintain stability, thus leading to toxicity in the environment.

Thus, we need to shift to "green synthesis" that offers numerous benefits of eco friendliness and compatibility for biomedical applications, where toxic chemicals are not used for the synthesis protocol. The use of agricultural wastes [9] or plants and their parts, ${ }^{[10]}$ has emerged as an alternative to chemical synthetic procedures because it does not require elaborate processes such as intracellular synthesis and multiple purification steps or the maintenance of microbial cell cultures.[11]

In biological system, over production of highly reactive radical species or their precursor. leads to oxidative stress which has been observed in various disease such as cancer, cardiovascular disease, diabetes and arthritis.[12] In few studies antioxidant and free radical scavenging activities of Zinc Oxide nanoparticles in biological system has been described.[13]

Many studies have shown that Zinc Oxide nanoparticles induce various toxic effects, including cytotoxicity, genotoxicity, inflammation, and oxidative stress.[14] Zinc Oxide nanoparticles are also known to have anti-inflammatory properties by blocking pro-inflammatory cytokines, inhibiting mast cell proliferation and suppressing LPS induced COX-2 expression.[15]

Syzygium aromaticum commonly known as clove, is a median size tree (8-12 m) belonging to the Mirtaceae family native from the Maluku islands in east Indonesia. For many years the trade of clove and the search of this valuable spice has caused the economic development of this region.[16] This plant plays a vital role as a spice, but it's essential oils and other constituents also have important activities like including antimicrobial, antifungal, antioxidant, and antidiabetic.[17]

Cinnamon is a spice obtained from the inner bark of several tree species from the genus Cinnamomum. Cinnamon has many health benefits like-it has antioxidant [18], antiinflammatory properties, ${ }^{[19]}$ may reduce the risk of heart disease, lowers blood sugar level, protective against cancer, and anti-microbial properties.
The rationale of this study is that no study has been conducted so far in which the properties of Zinc Oxide nanoparticles reinforced with clove and cinnamon have been assessed. Hence the aim of the study was to assess the cytotoxicity, anti -inflammatory and antioxidant activity of Zinc Oxide nanoparticles reinforced with clove and cinnamon.

\section{METHODS}

\section{Study Design}

In vitro study.

\section{Preparation of Plant Extract}

Clove buds and cinnamon bark sticks were purchased from the market of South India and were powdered using a mixer grinder. $5 \mathrm{mg}$ of clove powder and $5 \mathrm{mg}$ of cinnamon powder was dissolved in $100 \mathrm{~mL}$ of distilled water. The solution was boiled in a heating mantle at $60{ }^{\circ} \mathrm{C}$ for 10 minutes until the bubbles appeared. The solution was then filtered using a funnel and a Whatman filter paper and collected in a conical flask to obtain the plant extract. Then the plant extract was transferred to an airtight container and refrigerated overnight.

\section{Synthesis of Zinc Oxide Nanoparticles Using Clove and Cinnamon Extract}

$20 \mathrm{mM}$ of Zinc Sulphate was prepared using $60 \mathrm{ml}$ of distilled water and mixed thoroughly. $40 \mathrm{ml}$ of the plant extract was added to this solution and was placed in the orbital shaker. Colour change of the solution was noted every $2 \mathrm{~h}$. Readings were recorded every $2 \mathrm{~h}$ in U V Spectrophotometer and after around 36 hours, centrifugation was done at $7000 \mathrm{rpm}$ for 10 minutes. Zinc Oxide nanoparticles pellets reinforced with clove and cinnamon were obtained after centrifugation.

\section{Cytotoxic Effect}

The cytotoxicity of Zinc Oxide nanoparticles reinforced with clove and cinnamon extract was assessed using Brine shrimp assay. 12 well ELISA plates were taken and to each plate 6-8 $\mathrm{ml}$ of saltwater was added; followed by adding 10 nauplii to each well. Zinc oxide nanoparticles reinforced with clove and cinnamon was added to each well at different concentrations ( $5 \mu \mathrm{L}, 10 \mu \mathrm{L}, 20 \mu \mathrm{L}, 30 \mu \mathrm{L}, 50 \mu \mathrm{L}$ ) and was then incubated for $24 \mathrm{~h}$. After $24 \mathrm{~h}$, the total number of live and dead nauplii was counted and the mortality rate was checked.

$\%$ death $=\frac{\text { Number of dead nauplii }}{\text { Number of dead nauplii }- \text { number of live nauplii }} \times 100$

\section{Anti-Inflammatory Activity}

\section{Test Group}

$10 \mu \mathrm{L}, 20 \mu \mathrm{L}, 30 \mu \mathrm{L}, 40 \mu \mathrm{L}$ and $50 \mu \mathrm{L}$ of the nanoparticles was taken in 5 test tubes respectively. To each test tube $2 \mathrm{ml}$ of $1 \%$ Bovine Serum Albumin (BSA) was added. $390 \mu \mathrm{L}, 380 \mu \mathrm{L}, 370$ $\mu \mathrm{L}, 360 \mu \mathrm{L}$ and $350 \mu \mathrm{L}$ of distilled water was added to the test tube containing $10 \mu \mathrm{L}, 20 \mu \mathrm{L}, 30 \mu \mathrm{L}, 40 \mu \mathrm{L}$ and $50 \mu \mathrm{L}$ of nanoparticles respectively. 


\section{Control Group}

$2 \mathrm{~mL}$ of Dimethyl Sulphoxide (DMSO) was added to $2 \mathrm{~mL}$ of BSA solution.

\section{Standard Group}

$10 \mu \mathrm{L}, 20 \mu \mathrm{L}, 30 \mu \mathrm{L}, 40 \mu \mathrm{L}$ and $50 \mu \mathrm{L}$ of Diclofenac Sodium was taken in 5 test tubes respectively. To each test tube $2 \mathrm{~mL}$ of $1 \%$ Bovine Serum Albumin (BSA) was added. The test tubes were incubated at room temperature for 10 minutes. Then they were incubated in water bath at $55^{\circ} \mathrm{C}$ for around 10 minutes. Absorbance was measured at $660 \mathrm{~nm}$ in UV Spectrophotometer.

$\%$ Inhibition was calculated using the following formula:

$\%$ of inhibition $=\frac{\text { Control OD }- \text { Sample OD }}{\text { Control OD }} \times 100$

\section{Antioxidant Activity}

\section{Test Group}

$10 \mu \mathrm{L}, 20 \mu \mathrm{L}, 30 \mu \mathrm{L}, 40 \mu \mathrm{L}$ and $50 \mu \mathrm{L}$ of the nanoparticle was taken in 5 test tubes respectively. To each test tube $1 \mathrm{ml}$ of DPPH (2, 2-diphenyl-1-picrylhydrazyl) was added. $1990 \mu \mathrm{L}$, $1980 \mu \mathrm{L}, 1970 \mu \mathrm{L}, 1960 \mu \mathrm{L}$ and $1950 \mu \mathrm{L}$ of $50 \%$ methanol solution was added to the test tube containing $10 \mu \mathrm{L}, 20 \mu \mathrm{L}, 30$ $\mu \mathrm{L}, 40 \mu \mathrm{L}$ and $50 \mu \mathrm{L}$ of nanoparticles respectively.

\section{Control Group}

$1 \mathrm{~mL}$ of DPPH was added to $2 \mathrm{~mL}$ of methanol solution.

\section{Standard Group}

Ascorbic acid was used as standard

The test tubes were incubated in a dark cupboard for around 20 minutes. Absorbance was measured at $517 \mathrm{~nm}$ in UV Spectrophotometer.

\% Inhibition was calculated using the following formula:

$\%$ of inhibition $=$

$\underline{\text { Control Absorbance - Sample Absorbance }}$ CControl Absorbance

\section{RESULTS}

Table 1 depicts the cytotoxicity of Zinc Oxide Nanoparticles reinforced with and cinnamon extract. At $5 \mu \mathrm{L}$ concentration there was a death of $20 \%$ of nauplii, at 10 and $20 \mu \mathrm{L}$ there was a death of $30 \%$ of nauplii, at $30 \mu \mathrm{L}$ there was a death of $40 \%$ of nauplii and at $50 \mu \mathrm{L}$ there was a death of $50 \%$ of nauplii. It was seen that as the concentration increased the cytotoxicity of the nanoparticles increased.

\begin{tabular}{|ccc|}
\hline Concentration $(\boldsymbol{\mu L})$ & Viable Nauplii & \% Death \\
5 & 8 & 20 \\
10 & 7 & 30 \\
20 & 7 & 30 \\
30 & 6 & 40 \\
50 & 5 & 50 \\
\hline \multicolumn{2}{|c|}{ Table 1. Cytotoxicity of Zinc Oxide Nanoparticles } \\
Reinforced with Clove and Cinnamon Extract \\
\hline
\end{tabular}
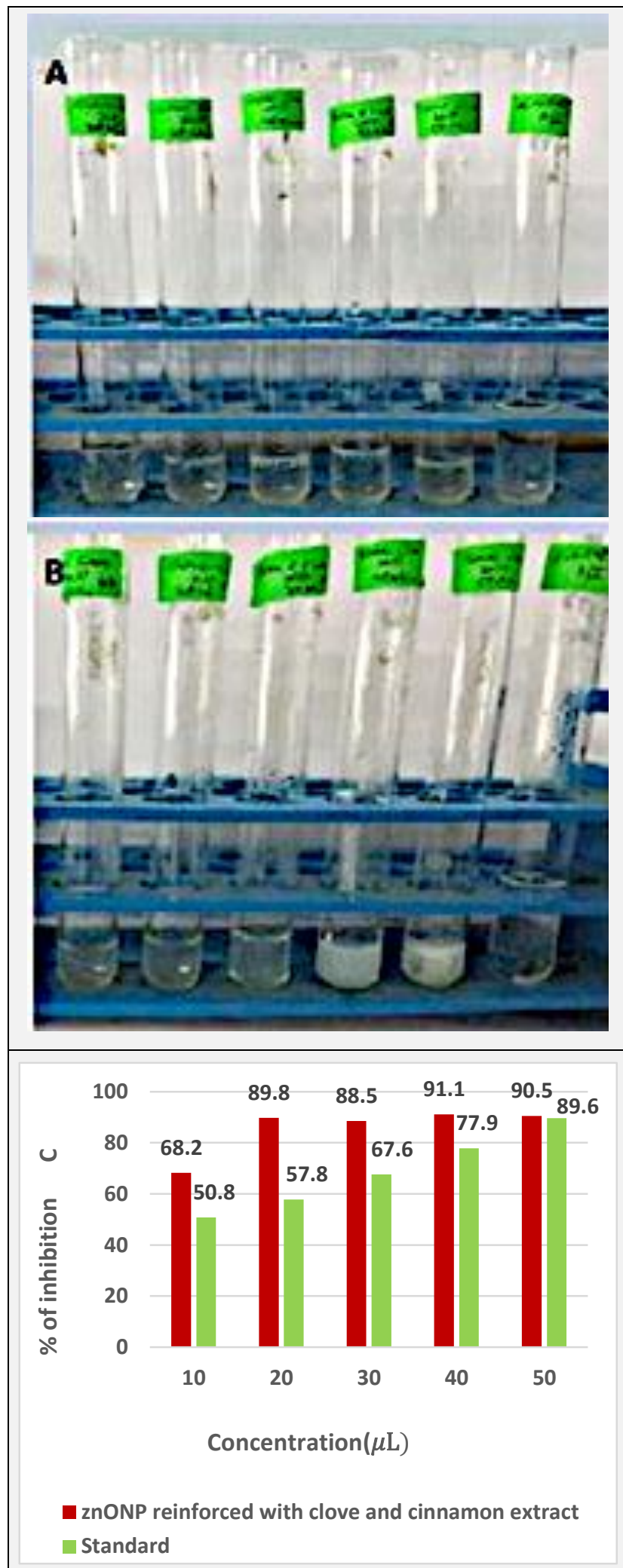

Figure 1. Anti-Inflammatory Property of Zinc Oxide Nanoparticles Reinforced with Clove and Cinnamon Extract

A-Pre-Incubation B-Post-Incubation C-Various Concentrations Compared with Standard Values 

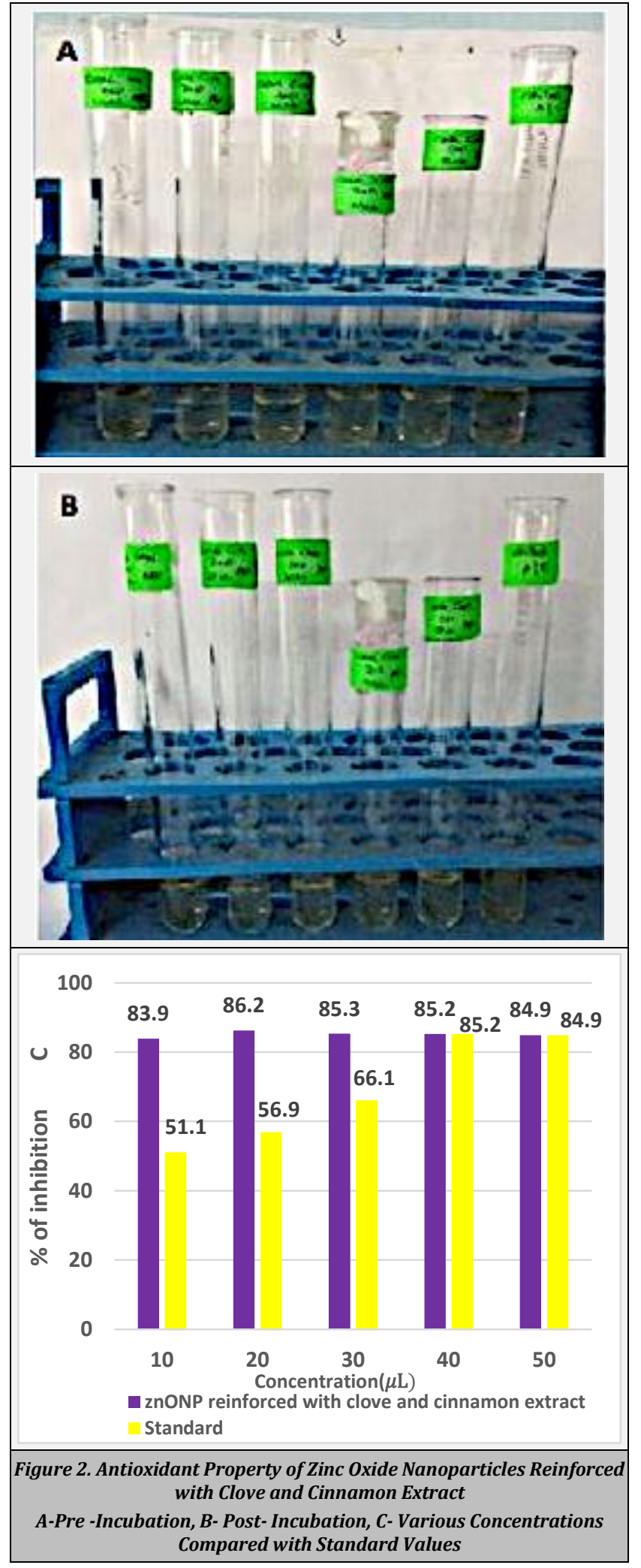

Figure $2 \mathrm{~A}$ depicts the anti- inflammatory property of Zinc Oxide nanoparticles reinforced with clove and cinnamon extract pre-incubation. Figure $2 \mathrm{~B}$ depicts the antiinflammatory property of Zinc Oxide nanoparticles reinforced with clove and cinnamon extract post-incubation. Figure $2 \mathrm{C}$ depicts the anti- inflammatory property of Zinc Oxide nanoparticles reinforced with clove and cinnamon extract at various concentrations compared with the standard values.
It was found that the values for anti-inflammatory property of nanoparticles was higher than the standard values at all concentrations. Percentage of inhibition was $68.2 \%$ at 10 $\mu \mathrm{L}$ concentration, $89.8 \%$ at $20 \mu \mathrm{L}, 88.5 \%$ at $30 \mu \mathrm{L}$ and highest at $40 \mu \mathrm{L}(91.1 \%)$ and $50 \mu \mathrm{L}(90.5 \%)$

Figure 3 A depicts the antioxidant property of Zinc Oxide nanoparticles reinforced with clove and cinnamon extract preincubation. Figure $3 \mathrm{~B}$ depicts the antioxidant property of Zinc Oxide nanoparticles reinforced with clove and cinnamon extract post-incubation. Figure $3 \mathrm{C}$ depicts the antioxidant property of Zinc Oxide nanoparticles reinforced with clove and cinnamon extract at various concentrations compared with the standard values.

The values for antioxidant property of nanoparticles was found to be higher than the standard values at all concentrations except at $50 \mu \mathrm{L}$. Percentage of inhibition was $83.9 \%$ at $10 \mu \mathrm{L}$ concentration, $86.2 \%$ at $20 \mu \mathrm{L}, 85.3 \%$ at $30 \mu \mathrm{L}$, $85.2 \%$ at $40 \mu \mathrm{L}$ and $84.9 \%$ at $50 \mu \mathrm{L}$.

\section{DISCUSSION}

There has been a rapid evolution of nanoparticle synthesis recently as compared to the early part of the century.[20] Earlier, physio-chemical methods were involved in nanoparticle synthesis. Even though less time is utilized for synthesizing large quantities of nanoparticles using conventional physical and chemical methods, toxic chemicals are required as capping agents to maintain stability, thus leading to toxicity in the environment. Keeping this in consideration, green nanotechnology using plants is emerging as an eco-friendly alternative, as plant extract mediated biosynthesis of nanoparticles is cost-effective [21]. We therefore undertook this study to evaluate the cytotoxicity, anti-inflammatory and antioxidant property of Zinc Oxide nanoparticles reinforced with clove and cinnamon extract.

In the present study it was seen that at $5 \mu \mathrm{L}$ concentration there was a death of $20 \%$ of nauplii, at 10 and $20 \mu \mathrm{L}$ there was a death of $30 \%$ of nauplii, at $30 \mu \mathrm{L}$ there was a death of $40 \%$ of nauplii and at $50 \mu \mathrm{L}$ there was a death of $50 \%$ of nauplii. Percentage of inhibition of protein denaturation (antiinflammatory activity) was $68.2 \%$ at $10 \mu \mathrm{L}$ concentration, $89.8 \%$ at $20 \mu \mathrm{L}, 88.5 \%$ at $30 \mu \mathrm{L}$ and highest at $40 \mu \mathrm{L}(91.1 \%)$ and $50 \mu \mathrm{L}$ (90.5\%). Percentage of inhibition of DPPH free radicals (antioxidant activity) was $83.9 \%$ at $10 \mu \mathrm{L}$ concentration, $86.2 \%$ at $20 \mu \mathrm{L}, 85.3 \%$ at $30 \mu \mathrm{L}, 85.2 \%$ at $40 \mu \mathrm{L}$ $(85.2 \%)$ and $84.9 \%$ at $50 \mu \mathrm{L}$.

As the concentration increased the cytotoxicity, antiinflammatory and antioxidant activity of the nanoparticles increased. The highest percentage of death of nauplii was at 50 $\mu \mathrm{L}$ concentration of Zinc Oxide nanoparticles reinforced with clove and cinnamon extract. The values for anti-inflammatory property of Zinc Oxide nanoparticles was higher than the standard values at all concentrations. Percentage of Inhibition was highest at $50 \mu \mathrm{L}\left(90.5 \%\right.$; $\left.\mathrm{IC}_{50}=0.095 \mu \mathrm{g} / \mathrm{mL}\right)$. The values for antioxidant property of nanoparticles was found to be higher than the standard values at all concentrations except at $50 \mu \mathrm{L}$.

Many studies have been conducted to assess the cytotoxicity of Zinc Oxide nanoparticles, clove and cinnamon. [22-27] The mechanisms of cytotoxicity from Zinc 
Oxide nanoparticles are not yet entirely understood, but the generation of hydroxyl radicals $\left(\mathrm{OH}^{\circ}\right)$, superoxide anion, and perhydroxyl radicals from the surface of Zinc Oxide are believed to be major components. ${ }^{[28]}$ High eugenol content in clove makes it cytotoxic. ${ }^{[29]}$ Hence they can be used against cancer cells.

Studies have also revealed that Zinc Oxide nanoparticles, clove and cinnamon have anti-inflammatory and antioxidant properties.[30-41] Zinc Oxide nanoparticles are known to have anti-inflammatory properties by blocking pro-inflammatory cytokines, inhibiting mast cell proliferation and suppressing LPS induced COX-2 expression. Antioxidant Zinc Oxide nanoparticles is due to release of hydrogen which reduces DPPH free radical easily.[42]

Anti-inflammatory and antioxidant of clove is due to its high eugenol content. Eugenol is a natural phenolic compound which reduces DPPH free radical by easily donating hydrogen.[43] Different flavonoids isolated from cinnamon have anti-inflammatory free-radical-scavenging activities. ${ }^{[44]}$

Based on the findings of the study we can say that reinforcing zinc oxide nanoparticles with clove and cinnamon has a synergistic effect and can be used as an alternative to commercially available anti-inflammatory and antioxidant agents.

\section{Limitations}

The study was conducted in vitro, so it cannot be assumed that the results of cytotoxicity, anti-inflammatory activity and antioxidant activity could be translated into clinical effectiveness.

\section{Recommendations}

- This product can be given to the patients in the form of a mouthwash.

- In further studies, in vivo studies are recommended with people' acceptance values as well.

\section{CONCLUSIONS}

Findings from this study suggests that zinc oxide nanoparticles reinforced with clove and cinnamon extract have a potential as an anti-cancer, anti-inflammatory, and antioxidant agent and can be used as an alternative to commercially available products.

\section{ACKNOWLEDGEMENT}

We would like to thank Dr. S. Rajeshkumar from the Department of Pharmacology, Saveetha Dental College for guiding us in the study.

\section{REFERENCES}

[1] Rico CM, Majumdar S, Duarte-Gardea M, et al. Interaction of nanoparticles with edible plants and their possible implications in the food chain. J Agric Food Chem 2011;59(8):3485-98.

[2] Daniel MC, Astruc D. Gold nanoparticles: assembly, supramolecular chemistry, quantum-size related properties and applications towards biology, catalysis and nanotechnology. Chem Rev 2004;104(1):293-346.

[3] Gnanasangeetha D, Thambavani SD. One pot of zinc oxide nanoparticles via chemical and green method. Research Journal of Material Science 2013;1(7):1-8.

[4] Guzmán MG, Dille J, Godet S. Synthesis of silver nanoparticles by chemical reduction method and their antibacterial activity. International Journal of Chemical and Biomolecular Engineering 2009;2(3):104-11.

[5] Cho JM. Biosynthesis of zinc oxide nanoparticles using Euphorbia Milii leaf extract-a green approach. Journal Bull Korean Chem Soc 2009;30:1616-8.

[6] Yiamsawas D, Savanitchakul KB, Supamonkon WKW. Effect of con centration on the optical and solid state properties of zinc oxide thin films deposited by aqueous chemical growth. Journal of Microscopy Society of Thailand 2009;23:75-8.

[7] Chang H, Tsai MH. Synthesis and characterization of zinc oxide nanoparticles having prism shape by a novel gas condensation process. Rev Adv Mater Sci 2008;18:73443.

[8] Li H, Wang J, Liu H, et al. Zinc oxide films prepared by solgel method. J Cryst Growth 2005;275(1-2):e943-e6.

[9] Kumar B, Smita K, Cumbal L, et al. Green synthesis of silver nanoparticles using Andean blackberry fruit extract. J Saudi Chem Soc 2017;21:S293-S8.

[10] Haverkamp RG, Marshall AT. The mechanism of metal nanoparticle formation in plants: limits on accumulation. J Nanopart Res 2009;11(6):1453-63.

[11] Saifuddin N, Wong CW, Yasumira AAN. Biosynthesis of zinc oxide nanoparticles using Ixora Coccinea leaf extract-a green approach. E-Journal of Chemistry 2009;6:61-70.

[12] Nash KM, Ahmed S. Nanomedicine in the ROS-mediated pathophysiology: applications and clinical advances. Nanomedicine 2015;11(8):2033-40.

[13] Singh BN, Rawat AKS, Khan W, et al. Biosynthesis of stable antioxidant $\mathrm{ZnO}$ nanoparticles by Pseudomonas aeruginosa rhamnolipids. PLoS One 2014;9(9):e106937.

[14] Fernández-Cruz ML, Lammel $T$, Connolly $M$, et al. Comparative cytotoxicity induced by bulk and nanoparticulated $\mathrm{ZnO}$ in the fish and human hepatoma cell lines PLHC-1 and Hep G2. Nanotoxicology 2013;7(5):935-52.

[15] Agarwal H, Nakara A, Shanmugam VK. Anti-inflammatory mechanism of various metal and metal oxidenanoparticles synthesized using plant extracts: a review. Biomedicine and Pharmacotherapy 2019;109:2561-72.

[16] Kamatou GP, Vermaak I, Viljoen AM. Eugenol--from the remote Maluku Islands to the international market place: a review of a remarkable and versatile molecule. Molecules 2012;17(6):6953-81.

[17] Cortes DF, Fernandes de Souza CR, Oliveira WP. Clove (Syzygium aromaticum): a precious spice. Asian Pacific Journal of Tropical Biomedicine 2014;4(2):90-6.

[18] Lin CC, Wu SJ, Chang CH, et al. Antioxidant activity of Cinnamon cassia. Phytother Res 2003;17(7):726-30. 
[19] Julianti E, Rajah KK, Fidrianny I. Antibacterial activity of ethanolic extract of Cinnamon Bark, Honey and their combination effects against Acne-Causing Bacteria. Sci Pharm 2017;85(2):19.

[20] Andersson M, Pedersen JS, Palmqvist AEC. Silver nanoparticle formation in microemulsions acting both as template and reducing agent. Langmuir 2005;21(24):11387-96.

[21] Chandran SP, Chaudhary M, Pasricha R, et al. Synthesis of gold nanoparticles and silver nanoparticles using Aloe Vera plant extract. Biotechnol Progr 2006;22(2):577-83.

[22] Ng TC, Yong LQ, Hande MP, et al. Zinc oxide nanoparticles exhibit cytotoxicity and genotoxicity through oxidative stress responses in human lung fibroblasts and Drosophila melanogaster. Int J Nanomedicine 2017;12:1621-37.

[23] Reddy RNA, Srividya I. Evaluation of in vitro cytotoxicity of zinc oxide ( $\mathrm{ZnO}$ ) nanoparticles using human cell lines. Journal of Toxicology and Risk Assessment 2018;4(1):009.

[24] Kouidhi B, Zmantar T, Bakhrouf A. Anticariogenic and cytotoxic activity of clove essential oil (Eugenia caryophyllata) against a large number of oral pathogens. Annals of Microbiology 2010;60(4):599-604.

[25] Dwivedi V, Shrivastava R, Hussain S, et al. Comparative anticancer potential of clove (Syzygium aromaticum) - an Indian spice - against cancer cell lines of various anatomical origin. Asian Pacific Journal of Cancer Prevention 2011;12(8):1989-93.

[26] Singh R, Koppikar SJ, Paul P, et al. Comparative analysis of cytotoxic effect of aqueous cinnamon extract from Cinnamomum zeylanicum bark with commercial cinnamaldehyde on various cell lines. Pharmaceutical Biology 2009;47(12):1174-9.

[27] Unlu M, Ergene E, Unlu GV, et al. Composition, antimicrobial activity and in vitro cytotoxicity of essential oil from Cinnamomum zeylanicum Blume (Lauraceae). Food and Chemical Toxicology: an International Journal published for the British Industrial Biological Research Association 2010;48(11):3274-80.

[28] Namvar F, Rahman HS, Mohamad R, et al. Cytotoxic effects of biosynthesized Zinc Oxide Nanoparticles on Murine Cell. Evidence Based Complementary and Alternative Medicine 2015;2015:593014.

[29] Prashar A, Locke IC, Evans CS. Cytotoxicity of clove (Syzygium Aromaticum) oil and its major components to human skin cells. Cell Prolif 2006;39(4):241-8.

[30] Reddy KM, Feris K, Bell J, et al. Selective toxicity of zinc oxide nanoparticles to prokaryotic and eukaryotic systems. Applied Physics Letters 2007;90(213902):2139021-3.

[31] Sarwar S, Chakraborti S, Bera S, et al. The antimicrobial activity of $\mathrm{ZnO}$ nanoparticles against Vibrio Cholerae: variation in response depends on biotype. Nanomedicine 2016;12(6):1499-509.

[32] Daniel AN, Sartoretto SM, Schmidt G, et al. Antiinflammatory and antinociceptive activities A of eugenol essential oil in experimental animal models. Revista Brasileira de Farmacognosian 2009;19(1B):212-7.

[33] Agbaje E. Anti-inflammatory effects of aqueous extract of dry clove flower buds. International Journal of Natural and Applied Sciences 2009;5(1).

[34] Gunawardena D, Karunaweera N, Lee S, et al. Antiinflammatory activity of cinnamon (C. Zeylanicum and C. Cassia) extracts - identification of E-cinnamaldehyde and o-methoxy cinnamaldehyde as the most potent bioactive compounds. Food and Function 2015;6(3):910-9.

[35] Xuesheng $H$, Tory LP. Anti-inflammatory activity of Cinnamon (Cinnamomum Zeylanicum) bark essential oil in a human skin disease model. Phytother Res 2017;31(7):1034-8.

[36] Tasgin E. Green synthesis of zinc oxide ( $\mathrm{ZnO}$ ) nanoparticles and determination of it's antioxidant and anti-radicalic activity. Journal of Chromatography \& Separation Techniques 2016;7(Suppl 6):81.

[37] Jeba YJ, Ratney J, David BS. Evaluation of in-vitro anticancer and antioxidant activity of zinc oxide nanoparticle by chemical and green method. International Conference on Nanotechnology: The Fruition of Science 2017: p. 10-5.

[38] Gülçin I, Şat IG, Beydemir S, et al. Comparison of antioxidant activity of clove (Eugenia caryophylata Thunb) buds and lavender (Lavandula stoechas L). Food Chemistry 2004;87(3):393-400.

[39] Jirovetz L, Buchbauer G, Stoilova I, et al. Chemical composition and antioxidant properties of Clove leaf essential oil. J Agric Food Chem 2006;23;54(17):6303-7.

[40] Yang CH, Li RX, Chuang LY. Antioxidant activity of various parts of Cinnamomum cassia extracted with different extraction methods. Molecules 2012;17(6):7294-304.

[41] Abeysekera WPKM, Premakumara GAS, Ratnasooriya WD. In vitro antioxidant properties of leaf and bark extracts of Ceylon Cinnamon (Cinnamomum zeylanicum Blume). Tropical Agricultural Research 2013;24(2):12838.

[42] Bhakya S, Muthukrishnan S, Sukumaran M, et al. Biogenic synthesis of silver nanoparticles and their antioxidant and antibacterial activity. Appl Nanosci 2015;10:1-12.

[43] Bondet V, Brand-Williams W, Berset C. Kinetics and mechanisms of antioxidant activity using the DPPH free radical method. Lebensm Wiss Technol - Food Science \& Technology 1997;30(6):609-15.

[44] Okawa M, Kinjo J, Nohara T, et al. DPPH (1,1-diphenyl-2picrylhydrazyl) radical scavenging activity of flavonoids obtained from some medicinal plants. Biological and Pharmaceutical Bulletin 2001;24(10):1202-5. 